\title{
Toward a synthetic economic systems modeling tool for sustainable exploitation of ecosystems
}

\author{
Colin Richardson, Jerry Courvisanos, ${ }^{2}$ and John W. Crawford ${ }^{3}$ \\ ${ }^{1}$ Social Computing Group, William Penney Laboratory, Imperial College, London, United Kingdom. 'University of Ballarat, \\ Ballarat, Victoria, Australia. 'University of Sydney, Faculty of Agriculture, Food and Natural Resources, Sydney, New South \\ Wales, Australia \\ Address for correspondence: John W. Crawford, Faculty of Agriculture, Food and Natural Resources, Suite 411, Biomedical \\ Building, 1 Central Avenue, Australian Technology Park, University of Sydney, Eveleigh, N.S.W. 2015. Australia. \\ john.crawford@sydney.edu.au
}

Environmental resources that underpin the basic human needs of water, energy, and food are predicted to become in such short supply by 2050 that global security and the well-being of millions will be under threat. These natural commodities have been allowed to reach crisis levels of supply because of a failure of economic systems to sustain them. This is largely because there have been no means of integrating their exploitation into any economic model that effectively addresses ecological systemic failures in a way that provides an integrated ecological-economic tool that can monitor and evaluate market and policy targets. We review the reasons for this and recent attempts to address the problem while identifying outstanding issues. The key elements of a policy-oriented economic model that integrates ecosystem processes are described and form the basis of a proposed new synthesis approach. The approach is illustrated by an indicative case study that develops a simple model for rainfed and irrigated food production in the Murray-Darling basin of southeastern Australia.

Keywords: theory; economics; ecosystems

Preferred citation: Colin Richardson, Jerry Courvisanos, and John W. Crawford. 2011. Toward a synthetic economic systems modeling tool for sustainable exploitation of ecosystems in "Ecological Economics Reviews." Robert Costanza, Karin Limburg \& Ida Kubiszewski, Eds. Ann. N.Y. Acad. Sci. 1219: 171-184.

\section{Background}

There is now a significant accumulation of reliable data to suggest that humanity will face historically unprecedented challenges in the next 20-40 years. In the main, these relate to a level of natural resource use that we are already committed to, but which cannot be met within the time constraints, even using optimistic assessments of supply and feasible technologies. They include consumption levels of energy, water, and soil - the basic requisites of life-and constituents for which there is no alternative substitute. Moriarty and Honnery present a strong case that the projected doubling of energy demand by 2050 will not be met, and indeed that we will struggle to maintain even the present levels of energy use, irrespective of alternative technology options. In relation to water, it has been estithe world's population will be in severe water stress by 2030 . Finally, the current level of soil degradation is such that $40 \%$ of the world's agricultural soil is so severely degraded that its productivity is significantly reduced, and the rate of soil loss by erosion exceeds its natural replenishment rate in developed and developing countries by factors of 36 and 54, respectively. ${ }^{2}$ Not enough is known to calculate whether the soil resource can meet the nutritional and calorific demands of the doubling of food supply required by projected 2050 consumption levels. These are "wicked" problems in the sense that potential routes to alleviating one exacerbate the others. For example, options to increase water supply by desalination are frustrated by shortfalls in energy supply, and the potential to increase food supply is limited both by water shortage and the significant energy demands of fertilizer production. 
Australia, and whose principal city is the world's largest black coal exporting port. While coal will remain an important option for energy production in the foreseeable future it also contributes more than $40 \%$ of global $\mathrm{CO}_{2}$ emissions, and mining activities in the Hunter Valley threaten food production and have impacted on human health, water quality, and biodiversity.

Recently, the world reached a significant milestone. For the first time since the emergence of agriculture and the birth of civilization, the number of people living in cities has exceeded the number living in the country. While this trend undoubtedly brings benefits associated with economies of scale including affordable services, enhanced innovation rates, and wealth, it brings its own challenges. Not least among these is the strain that cities place on the local natural resources, the resultant requirement for spatial translocation of resources from remote areas and the concentrated production of waste and pollution. In many cases, cities historically expanded from rural communities with the result that, although they occupy only $0.03 \%$ of the total land area, they occupy 3\% of arable land. ${ }^{9}$ вy 2030, the urban population is projected to double in developing countries and occupy nearly $7 \%$ of arable land, exacerbating the provision of soil for food production. Rural infrastructure development has an even greater per capita impact on land area. Most significantly of all, however, increasing urbanization means that the majority of people will most often experience the natural environment in an urban rather than a rural context. ${ }^{4}$ This is likely to contribute to a growing disconnect between nature and people that will, as explained in the following section, further reinforce na"1ve perceptions of the links between environment and society. Ironically, as the need for a better connect has never been more important, the forces acting against it have never been greater.

\section{Aim of the study}

With such significant issues at stake, it is particularly important to have a policy-oriented model that in-

${ }^{a}$ For an example of this ecological strain on advanced developed highly urbanized cities, see Australian cities studies. For a critical review of such studies in the context of the periphery of urban cities, see Ref. 8.

Richardson et al.

tegrates these ecological concerns with the drivers of the economic system. In this way, the current and projected levels of natural resource consumption can be monitored to determine unsustainable levels. We need such an effective model as an evaluation tool before we can begin to identify and steer the key drivers in a more appropriate sustainable direction. In this paper we will briefly review the shortfalls in mainstream economic theory that create this need for the development of an integrated model. It is argued that economic models built on mainstream economic theory lead to incorrect policy decisions that result in the unsustainable use of certain kinds of natural resources. The theoretical considerations have received detailed attention elsewhere, and alternative approaches have been proposed. ${ }^{10-12}$ However, we will focus attention on an approach to developing an integrated (or synthetic) modelthatenables essential factorstobeconsidered, especially incorporating rural investor/producer behavior; the interactions between resources, and the appropriate level of granularity. This level of detail has not been attempted in previous integrated ecological-economic modeling.

We argue in this paper that creation of a unifying synthetic model is as essential a feature of any solution as it is in the physical sciences. This is primarily because it forces the need for a common grammar that links the different disciplinary contributions and, as a result, identifies the fundamental variables, boundary conditions, and relationships that drive the system forward. We propose that any economic model aiming to simulate empirical reality must contain a fusion of human, economic, and ecological dynamics and must embrace the resulting nonlinear network of interactions, in all its rich complexity. As such, we do not see the need to distinguish between specific "flavors" of economic theory, such as "ecological economics," "sustainability economics," and "environmental economics." These distinctions are subtle at best ${ }^{13}$ and can only raise barriers to progress. It is hard to imagine any economic system that does not interact with environmental systems, thus mainstream economic theory should evolve to deliver the required synthesis 
model. To illustrate the concepts and modeling approach, we describe progress toward the development of a synthetic ecological-economic systems model for the Murray-Darling river basin in eastern Australia. We show how rural investor/producer behavior, and the nonlinear interaction between commodities and the environment,can be modeled at anappropriatelevel of granularity. The consequences for the predicted dynamics of the system are profound, leading to cycles that incorporate time scales associated with both investor/producer behavior and the natural dynamics of the environmental system under consideration. The potential of this modeling approach to inform policy is also illustrated. Finally, we discuss the shortfalls of the model developed and provide a roadmap for improving ecological-economic synthesis modeling. 


\section{The disconnect between economics and natural ecosystems}

Theoretical ecology has a long history that has been extensively reviewed. ${ }^{14}$ Ecological models have evolved from being single-species, nonspatial, and linear to being complex, multispecies, spatial, and nonlinear. Levels of granularity have moved from assuming all individuals are identical to metapopulation models that group individuals into functional cohorts, and most recently to models where each individual is assumed to be different. Among the main conclusions that have emerged from these theoretical analyses, backed up by field observation, are the importance of the form of the interaction network between functional cohorts or individuals, ${ }^{15,16}$ the assumed level of granularity, ${ }_{17,18}$ nonlinear dynamics, ${ }_{19,20}$ and functional variation. ${ }^{18,21,22}$ The concept of fitness has moved on from being an intrinsic property of an individual to an emergent fitness "landscape," whose form is a consequence of the integrated dynamics of the community as a wholeinagivenenvironment. ${ }^{23}$ When evolutionary time scales are considered, the prevailing picture of an ecosystem is one of a complex adaptive system (CAS). In CAS, ${ }^{24}$ community-scale features emerge from interactions at lower levels, and these functional cohorts or individuals are themselves subject to evolution in their behavior.

Despite the special status given to it in the Rio Summit, the significance of biodiversity for the dynamics and function of ecosystems is not well established. ${ }^{25.26}$ Indeed, it is not clear what, if anything, isoptimized in ecosystems. While ecological communities progress through stages of development following disturbance toward a "climax" stage, they are never in equilibrium. Evolution by its very definition precludes this, and in addition we have the probable addition of internally driven dynamics, immigration, emigration, invasion, disease, and climatic perturbation, all contributing further to nonequilibrium behavior. The dynamical steady state of ecosystems is difficult to characterize and this is related to the uncertainty that surrounds the question of functional optimality. It stems from the fact that both these properties depend on the identification of a "potential function," namely some property of the ecosystem that is either maximized or minimized when the steady state is attained. Numerous attempts have been made to apply concepts borrowed from thermodynamics to ecosystems in order to identify this function. Even if this is found to be appropriate, the fact that ecosystems are so strongly coupled to the environment (i.e., "open”) and so far from equilibrium is likely to place them in the realm of nonlinear nonequilibrium thermodynamics. ${ }^{28}$ since an understanding of the physics of such systems is still far from complete, a description of ecosystems in these terms is still some way off. 27,2

To summarize: ecosystems are far from equilibrium, nonlinear, CASs whose emergent properties stem from the interactions between a large number of distinct functional types. The relation between structure and function of ecosystems remains elusive, as does a characterization of the steady state. These are the key features that should be reflected (and improved upon) in a synthetic model of the economy and environment.

As has been pointed out by Ayres, ${ }^{12}$ classical economics has assumed, since the time of Adam Smith, that market forces act as an "invisible hand," guiding and regulating supply and demand commodity flows until they come into perfect balance at the commodity's “equilibrium price.” Until recently, the natural resources that underpin so many of our basic needs for commodities have not been considered a fully integrated part of the economic system. Indeed, neoclassical or mainstream economic theory, as it impacts on policy today, is fundamentally inconsistent with what we know about how ecosystems interact with local and global economies. The most frequently used models fall into either of the two classes of econometric or general equilibrium approaches. The former bases future projections on statistical analyses of prior economic data and so is incapable of predicting the innovation processes and adaptive behavior that characterizes ecological systems. The latter approach assumes both the economic and ecological systems to be in equilibrium and, in addition, makes assumptions about optimal rational behavior. As already discussed in this section, none of these assumptions is of any relevance to ecological systems. More sophisticated approaches share common features with ecological systems, including coevolutionary individual-based behavioral models. ${ }^{10,31}$ These approaches are appealing because they possess many of the key features of a synthesis and the macroscopic economy is assumed to be an emergent property of the large number of individual interactions. ${ }^{32}$ However, here, as with ecological systems the question of granularity is important. In many of these models the individual "agents" can be individual investors, or institutions, such as banks. ${ }^{31}$ In ecology, this would be analogous to mixing descriptions at more than one level of granularity, for example, 
individuals and metapopulations, which is difficult to describe in measurable terms. Thus, as with ecosystems where the maximal (or minimal) function remains unknown, the definition of a neoclassical equilibrium in the economy is as elusive as the metrics that are required to characterize it. 
Intheintroduction to the classicworktheyedited, The Economics of Non-Convex Ecosystems, Dasgupta and Maler ${ }^{33}$ lament that

...except in the case of partial economic

systems [examples given] we still do not have a

clear understanding of the mechanisms by

which resources are allocated in non-convex

environments. So we economists continue to

rely on the convexity assumption, always hoping

that it is not an embarrassing simplification.

Ecologists have no comparable need to explore

the structure of convex sets (p. 1). Unlike the economy-wide model discussed in this paper, the

contributions selected by Dasgupta and Maler concern the economics and ecology of such partial systems as trees-grasses, shallow lakes, and boreal forests.

This need for convexity, like the homo oeconomicus axiom, the decreasing returns assumption, and a fixation on optimal (maximizing) outcomes, is a hallmark of neoclassical economics, for example, "The Optimal Depletion of Exhaustible Resources” by Dasgupta and Heal ${ }^{34}$ and Hotelling's rule, ${ }^{35}$ which define the net price path as a function of time, while maximizing rent as full extraction of a nonrenewable natural resource is approached. Regardless of the real-world situation, convex production and consumption sets are needed for a purely mathematical reason: They guarantee convergence on a supply/demand equilibrium —one that also is stable and Pareto optimal-in conventional mainstream economic models.

The standard assumptions of orthodox economics are increasingly being modified, introducing such considerations as infrequent "black swan" events from long-tailed risk distributions, increasing returns and behavioral considerations. By contrast, heterodox economists see promise in only two recent neoclassical developments: post-Walrasian economics ${ }^{36}$ andcomplexity economics as practiced at the Santa Fe Institute. ${ }^{37}$

Although many of the assumptions of neoclassical economic theory are at odds with ecological theory, such recent progress is suggestive of a convergence toward approaches that are less mutually exclusive. There remain gaps, but also opportunities for a closer synthesis.

\section{Ushering in a new synthesis}

Having identified and examined the disconnect between ecological and mainstream economic models for sustainable development that prevails in the theoretical and planning techniques adopted by both academia and public research authorities, our paper argues for an alternative modeling approach. This section outlines the rationale for this new approach that synthesizes the ecosystem and economic systems in the way envisioned by the ancient Greeks, when they used the word "economia" to refer to both systems simultaneously.

we suggest that a modeling approach that is nonlinear and multisectoral, and that includes adaptive feedback mechanisms over historical time, is a more appropriate way forward. It is based on the CASs approach already adopted for ecological studies, as discussed in the previous section. However, mainstream economists still use static equilibrium models that assume all individual separate units (consumers or firms) are identical and conduct independent microeconomic transactions. Rejection of two central elements of neoclassical economic models is the starting point for our synthesis with ecological models. One is methodological individualism and the other is static equilibrium. Instead of individuals, the unit of analysis in the proposed alternative approach is functional cohorts that can be modeled, based on the stylized facts that they portray. Notable cohorts are industry clusters of firms and workers, government authorities, and supplying/purchasing agents outside the region being modeled. Instead of static equilibrium economic transactions, the alternative is for modeling that operates in a time-dependent and uncertain world. Thus, the modeling approach is systems based and time dependent, allowing for the incorporation of both elements in their reconstructed form and then using them for analysis and planning of sustainable development. 
Market production and exchange within a fragile global ecological system can be modeled realistically with a nonlinear dynamic model that uses computer simulation to reproduce patterns of cohort behavior in the model based on stylized facts. Then the way the system adapts and changes over time can be seen through changes in the variables (and in such ratios as the realized profit rate and the incremental capital output ratio) over a succession of simulated historical short periods that can be represented as separate and discrete. Use of such an approach allows the tracing out the path of investment decisions and their impact on the economy. Recently two of the authors have embarked on building a sustainability model as a test bed for the evolution, investigation and trial simulations of a new synthesis of economics and ecology that does not have the same traditional tensions discussed above. ${ }^{40}$ This approach to economic modeling aims to significantly enhance current efforts by policy makers, agriculturists, and environmentalists to, first, stave off the looming environmental disasters that exist in places like the Murray-Darling river basin system, and then to rebuild it as an ecologically supported and sustainable economic system. In this way, a computer simulation model can be produced that provides a planning tool for decision makers, one that displays for them the interaction of economic and environmental changes. In the next section, we begin to apply this modeling approach to economic and ecological activity in a generic river basin based on southeastern Australian ecological conditions, as a first step toward creating the synthetic modeling planning tool for the actual Murray-Darling river basin.

For a synthetic model to be constructed, the concept of sustainable development needs to be defined and operationalized in order to identify the issues of sustainability that underlie any ecosystem and the economic activity that threatens, alters, or supports it. Sustainable development has become associated since 1987 with the publication of the "Bruntland report" ${ }^{, 41}$ and the World Bank pamphlet "environment, growth and development." Sustainable development is said to refer to economic development that "...meets the needs of the present without compromising the ability of future generations to meet their own needs" (p. 41). ${ }^{41}$ Vercelli provides a more specific definition, that economic development is "...considered sustainable only when future generations are guaranteed a set of options at least as wide as that possessed by the current generation” (p. 269). Many actions can be implemented in aiming toward this sustainable development concept by the functional cohorts modeled, including renewable energy, eco-efficiency, recycling, reduced planned obsolescence, and improved mass public transport. All such actions significantly address the ecological challenge, but at the same time generate economic development. It is the crucial decisions by business to invest in eco-innovation that enables sustainable development to be realized. The full actualization of such a sustainable development is a political issue and requires a deep analysis of its own. Suffice to state here that it is the public and political will to achieve such a goal that is necessary before this process can be taken any further.

Vercelli $^{42}$ argues that uncertainty in the market makes any optimization modeling based on substantive (or unbounded) rationality impossible to be expressed in any way that would have operational significance. The elements of irreversibility and complexity that arise over real historical time imply that an adaptive procedural (or bounded) rationality is required. This means that the objective of sustainable development can only be achieved in a cumulative process of "learning by doing" and acquiring knowledge through implementation of acceptable adaptive (nonoptimal) conventions and rules. Thus, adaptive feedback is a key element of

\footnotetext{
${ }^{b}$ For a short account of the genealogy of the term, see Vercelli. ${ }^{42}$ In fact Costanza and Daly ${ }^{43}$ acknowledge that "uncertainty itself is one of the critical factors that must be addressed in designing sustainable policies” (p. 45).
} 
any methodology that enables effective fusion of ecological and economic modeling for sustainable development.

With the appropriate modeling methodology identified and the goal of sustainable development specified, the task in this synthesis is to explicate an economic process for the implementation of this modeling methodology in order to arrive at agreed ecologically sustainable goals.

Two mid-20th century economists, Adolph Lowe and Michał Kalecki, analyzed how an economy can traverse from, one development path to another throughan adaptive modeling process. Together, the principles outlined by these two economists provide an economic policy framework for the paradigm shift that is needed $^{44}$ by traversing from the current unsustainable economic development path to one that is sustainable. It is for this type of paradigm shift that the modeling methodology is developed.

The framework is based on Adolph Lowe's recommended "instrumental analysis," a way of using "instruments" (i.e., specific policy tools) to achieve agreed goals. The analytical framework of Lowe $^{45}$ is designed to enable rules of formal logic to be applied to economic cause and effect sequences over historical time. Lowe calls this "...the search for the economic means suitable for the attainment of any stipulated end. To this procedure I have assigned the label of instrumental analysis” pp. 11-12). 45.

This search procedure works backward from ends to means, which Forstater ${ }^{47}$ calls "retroduction" in his explanation of the Lowe process.

Retroduction is a more effective policy process to achieveagoal becauseonedoes not "reach" for the goal; instead the goal is "lined up" with the means. The modeling approach presented here enables the agreed goals to be "lined up" and enumerated via policy experiments. Lowe ${ }^{45}$ adoptS cause-effect principles to set up public structural adjustment policies that are "lined up" for the traverse to desired goals. In the context of the analysis in this paper, the desired goal is sustainable development. Given public and political will to achieve such sustainable development, motivation, and voluntary conformity will ensure the success of this traverse path.

For Lowe, investment in infrastructure and capital stock is the central element of any traverse path
'See the excellent exposition of Lowe's work in Oakley.

to economic growth. Public investment policy in infrastructure and private investment in major capital works are the crucial focus of any instrumental analysis. For sustainable development, investment needs to shift away from the existing techno-economic paradigm (e.g., fossil fuel energy) to a new techno-economic paradigm that is ecologically sustainable (e.g., renewable energy). This new path to sustainabledevelopmentmustprimarilyconcentrateonthe type of investment that will carry, via effective demand, the economy forward into the long run. With uncertainty in real time, the "mistake-ridden private sector" is prone to investment instability that underminesanyeffectivetraversepath. ${ }^{49,}$ AS Lowe $^{45}$ notes, it is the insufficient order and coherence of privatesector investmentthatregularly stallsanddelays creation and commercialization of innovative investment projects. Helm and Pearce ${ }^{51}$ recognize this problem in relation to ecologically sustainable investment projects, and advocate public policy to internalize the social ecological costs of production by effective pricing (e.g., carbon tax) and appropriate infrastructure (e.g., renewable energy grid). These two aspects are incorporated simultaneously within the modeling approach and set the conditions for ecologically sustainable private innovation and investment. Thus, a combination of passive (e.g., pricing) and active (e.g., infrastructure) public structural adjustment policies are required to underpin the traverse to sustainable development, and the modeling approach presented here enables policy experiments to identify possible scenario outcomes.

The question arises as to what is the most appropriate and effective structural adjustment policy. Lowe advocates "regressive inferences," which

\footnotetext{
e See Freeman and Perez ${ }^{48}$ on the concept of a techno-economic paradigm. Simply put, it is the essential disruptive technological system that ushers in a new technological industrial revolution, for example, electricity generation and the World Wide Web. 'see also Richardson ${ }^{50}$ for details on lack of coordination in markets for investment and the systemic failures that this creates. Richardson goes on to specify how investment coordination through information agreements and industrial concentration can assist in developing micro-goals in policy-oriented strategies that can
} 
significantly avoid such big "mistakes" as the 2007-2008 Global Financial Crisis. 
is an iterative search process. Searching iteratively is the only policy option in a world of uncertainty where the optimization modeling approach of mainstream economic models cannot provide the necessary policy guidelines for traversing toward a completely new path of sustainable development. However, Lowe does not specify how this iterative process can be implemented. This critique can be addressed by adopting Michał Kalecki's "perspective planning."

Perspective planning involves incrementally adjusting the parameters to the policy tools in fashioning the means to the agreed sustainable development goal. This is achieved by specifying practical short-run targets that induce, through effective demand, innovations, in sustainable development investment that eventually add up to the long-run goal. Traverse to an eco-sustainable regime needs short-term feasible steps of iterative carbon pricing and physical infrastructure that are continually modeled and assessed in relation to targets set for long-run sustainable development. Targets need to be monitored and policies assessed at regular short-term "end points" to see whether it is necessary to revise (i) the policy settings, (ii) the short-term strategy tools, and (iii) the broad-based long-run scenario. A perspective plan with these goals needs to be setup to forma specifictraversepath inconsort with politically agreed ecological "rules" that deliver the type of ecological sustainability determined by the instrumental analysis.

Two elements in the political economy of sustainable development are required for the necessary traverse to be negotiated. One is the political environment that accepts this perspective planning process aimed at achieving agreed sustainability targets, such as a global target of 350 parts per million global carbon emissions ${ }^{53}$ and the Australian state of Victoria's target of $155 \mathrm{~L}$ per person per day. ${ }^{54}$ The other is a modeling approach that enables the iterative search process to incorporate both the economic and ecological variables in setting, monitoring and evaluating the policy targets, the tools used to achieve the targets, and the targets themselves to achieve sustainability. The first element is not the subject of this paper, the second one is.
The next section of the paper is an illustrative case study to show how modeling with adaptive feedback can be used to fuse together the economic and ecological variables into computer simulation exercises. These exercises examine the impact of set targets using specific policy tools, which then can be evaluated iteratively as more information is gained on progress of the policy implementation. The development of such a modeling approach also aims to have a spillover effect on the political element in that, if such a modeling process can be shown to be possible and effective, then governments and the public can be emboldened to push for such political change. The generic case study below is a precursor to modeling empirical water usage in the Murray-Darling river basin and showing the need to develop mandatory water targets for sustainability.

Case study: toward a
policy-oriented model of the
Murray-Darling basin

We illustrate what we believe to be the basis of an approach for integrating ecological and economic modeling with a generic river basin model (RBM) that has strong parallels with the Murray-Darling basin (MDB), concentrating on the economic characteristics of that particular region. The details of key equations used in the model are presented in Appendix A.

In "year zero" of the model, the river basin comprisesa stock of arable land,one thatslowly degrades over a century of simulated historical time due to water runoff from trend rainfall, exacerbated by irrigation runoff. The MDB's actual and trend rainfall figures (1910-2009) are inserted for years one through 100 . These reduce to "useable rainfalls" after subtracting evapotranspiration losses and there is a conversion from rainfall in millimeters to supplies of water in gigaliters: actual for rainfed crops and potential for irrigated crops. Demands for irrigation water may be cut back by policy decisions whenever irrigation allocations are set at less than $100 \%$ by a River Basin Commission (RBC) that administers the region. The RBC acts whenever a "drought severity index anomaly” exceeds zero, indicating that actual drought severity (low rainfalls combined with high maximum temperatures) has risen above its trend. 
Turning now to the river basin's economy, its land is equally suitable for growing crops of rain-fed wheat or irrigated rice for export to the rest of Australia (RoA), though mainly to the rest of the world (RoW). Except for labor and irrigation water, all farm inputs, items of capital stock and consumer commodities are sourced as imports from 
RoA/RoW. As the region issues no currency unit, its highly volatile balance of trade (exports minus imports) can have no impact on any interregional "exchange rates." These don't exist and, in any case, the river basin's RoW trade will hardly affect the Australian dollar's value, which mainly is determined by mining exports and financial flows based on interest rate differentials.

The supply of labor comes from the region's resident workforce, which experiences slow natural increase during the century. In any given year, the money wage paid to fieldhands has four determinants. It cannot fall below the previous year's level, will rise with both labor productivity and price inflation, and will fall as the rate of unemployment increases (which erodes the workers' bargaining power). The demand for farmworkers is directly linked with the total areas planted to rice and wheat. As an emergent property, labor demand turns out to be inversely related to the real wage in theshortterm. This is notnew or unexpected,but a well-established economic relationship that emerges (rather than being inserted) in our new approach. In the medium

term,however,labordemandturnsouttobe directly related to the real wage. This result will not surprise heterodox economists who understand the following sequence in historical time: higher real incomes raise the consumption element of aggregate demand, eventually leading to increased output and employment levels. Employment of fieldhands periodically rises and falls because the area planted cycles around an upward growth trend as farms of minimum economic size are established, switched between crops or abandoned in accordance with the "economic outlooks" entertained by farmers, concerning their wheat and/or rice plantings. (This growth trend is merely a secondary statistical implication of the primary cyclical behavior, which is endogenous to the model.)

The functional cohorts of rice or wheat farmers' economic outlooks are characterized by a single number for each crop: its "profitability gap” (zr\% or $\mathrm{zw} \% \mathrm{pa}$ ), the difference between its "return on capital" (expected profit rate) and its "cost of capital” (market interest rate plus risk premium). Stemming from all its previous history, in year zero the region inherits a situation where the gap for rice stands at $10.5 \%$ pa, while for wheat it is only $4.3 \%$ pa. Thus it is not surprising that in year one the area planted to rice expands by $2.4 \%$ whereas hectares under wheat rise by only $1.6 \%$. In fact, plantings increase whenever $z$ is positive, decrease if $z$ is negative and stay the same when $z$ is zero.' (If these crops' combined demand for land happens to exceed the hectares available, farmers anticipating the higher $\mathrm{zr}$ for rice will outbid the low zw wheat growers and secure all the land they want, leaving the residual area planted to wheat, i.e., the crop with lower expected profitability.)

Areas planted determine subsequent production and harvests of grains, whose export prices then fix each crop's market value. Thus "crop-in-field" investments by farmers are driven by the time series of profitability gaps, as too are their "landand-water" investments that maintain and improve farmland, together with all private irrigation infrastructures. (Public irrigation infrastructure is exogenous, being financed and built by Commonwealth and State governments, not by the RBC.) Farmers' land-and-waterinvestments, togetherwith RBC expenditures on agricultural research, agronomy, and extension, determine the fluctuating yields per hectare recorded when the river basin's crops of wheat and rice are annually harvested. The key mathematical relationships in the computer model of the river basin economy are set out in Appendix A.

Recalling that "economic outlooks"-expected profitability gaps-determine investment and production, hence, also the region's real gross domestic product (GDP), why does the model economy undergo endogenous business cycles rather than growing smoothly over time?

Figure 1 shows how real GDP (Yr) comprises the economy's wages bill (Wr), gross operating surplus (Rr), and taxation receipts (Tr), all adjusted for price inflation. Wages account for most of GDP, and even exceed it as year 100 looms. At that time, gross operating surplus goes negative: profits become losses and interest payments go overdue. (Had the simulation continued beyond year 100, the Rr cycle would have reached its trough, then moved into a new upswing phase, drawing $\mathrm{Yr}$ and $\mathrm{Wr}$ along in its wake.)

${ }^{g}$ The capital investment functions proposed by economists of all schools, both mainstream and heterodox, are shown to contain this profitability gap mechanism by Richardson and Romilly.

" In mainstream economics it is this year's $\mathrm{Yr}$ and $\mathrm{Wr}$ (or "market conditions") that explain this year's real 
profits 


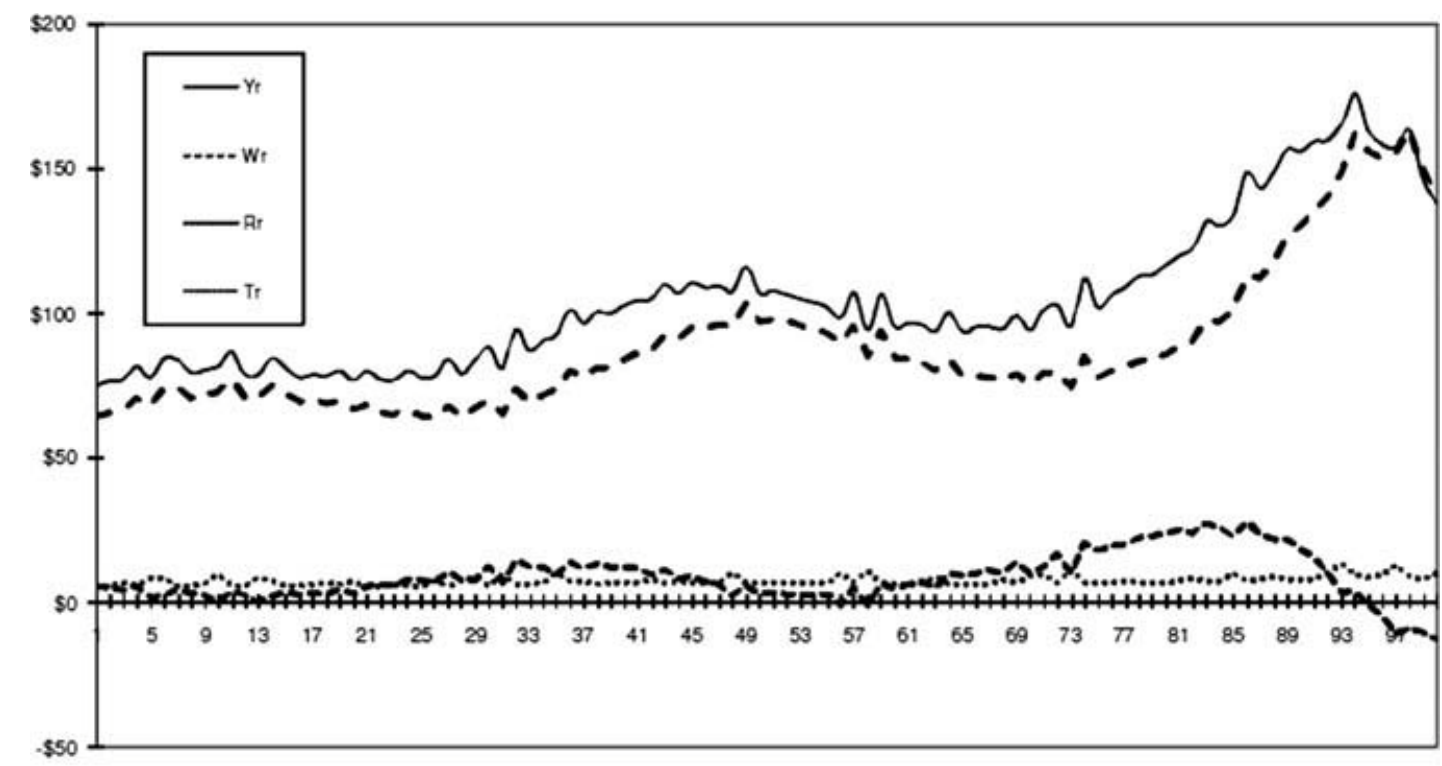

Time

Richardson et al. Economic systems modeling for sustainable ecosystems

Contra neoclassical economic theory, these cycles are endogenous, with exogenous shocks like unexpected changes in the world oil price, interest and exchange rates, prices of exports and imports, government expenditures, and shifts in consumers' tastes and preferences playing only a secondary role. (Similarly, irregularities in the otherwise smooth cycles of Figure 1 are caused by exogenous rainfall and temperature shocks to realized profitability.) The economic outlook for farmers is always uncertain, not merely risk laden. Econometric studies strongly suggest that the most recent realized financial results of business decision makers tend to loom largest in their minds as they develop their expectations of future sales and cost factors, hence also their outlooks concerning the profitability of next year's outlays on capital assets. Because of these considerations, and to keep things simple, this simulation model assumesabasic "staticexpectationsfunction" forprofitability outlooks: this year's profit rate is expected to

(included in Rr, along with interest earnings). But in our model, where historical time and "market outlooks" matter, it is last year's profits that explain this year's investment and GDP (hence also this year's Wr, linked as it is with Yr).
Figure 1. Real gross domestic product and its income components. Yr denotes real GDP, Wr denotes the economy's wages bill, $\mathrm{Rr}$ is the gross operating surplus, and $\operatorname{Tr}$ is the taxation receipt.

be the same as last year'srealized profit rate. With the general interest rate and crop-specific risk premium both known, each crop's expected profitability gap is determined by (equated to) the profit rate it realized after last year's harvest.

As an empirical fact, farmers are forever realizing financial results, both good and bad, that they never expected. They can and must develop expectations of their costs, sales, profits, and capital stock values, but have no control over the profit rate they will actually realize after the harvest comes in. The realized profitability of farming assets depends on a host of influences: export prices for rice and wheat, crop yields that fluctuate, RBC decisions over irrigation allocations and the price of this water, changing labor productivities and wages, the domestic prices of fertilizer and seeds, rentals for using (in this model, imported) fixed assets, and so on. Recall that in year zero the rice profitability gap (zr) was expected to be $10.5 \%$ pa, causing a rise in investment. However, that was followed by realized gaps of $9.7,8.9,3.6, \ldots \%$ pa, causing ever-smaller increases in the area planted to rice. Similarly, the wheat profitability gap (zw) started out at $4.3 \%$ pa, but was followed by gaps of 3.2, $2.7,2.2, \ldots \%$ pa, which also ameliorated the business cycle's upswing for that product. Figure 2 shows what happened. 



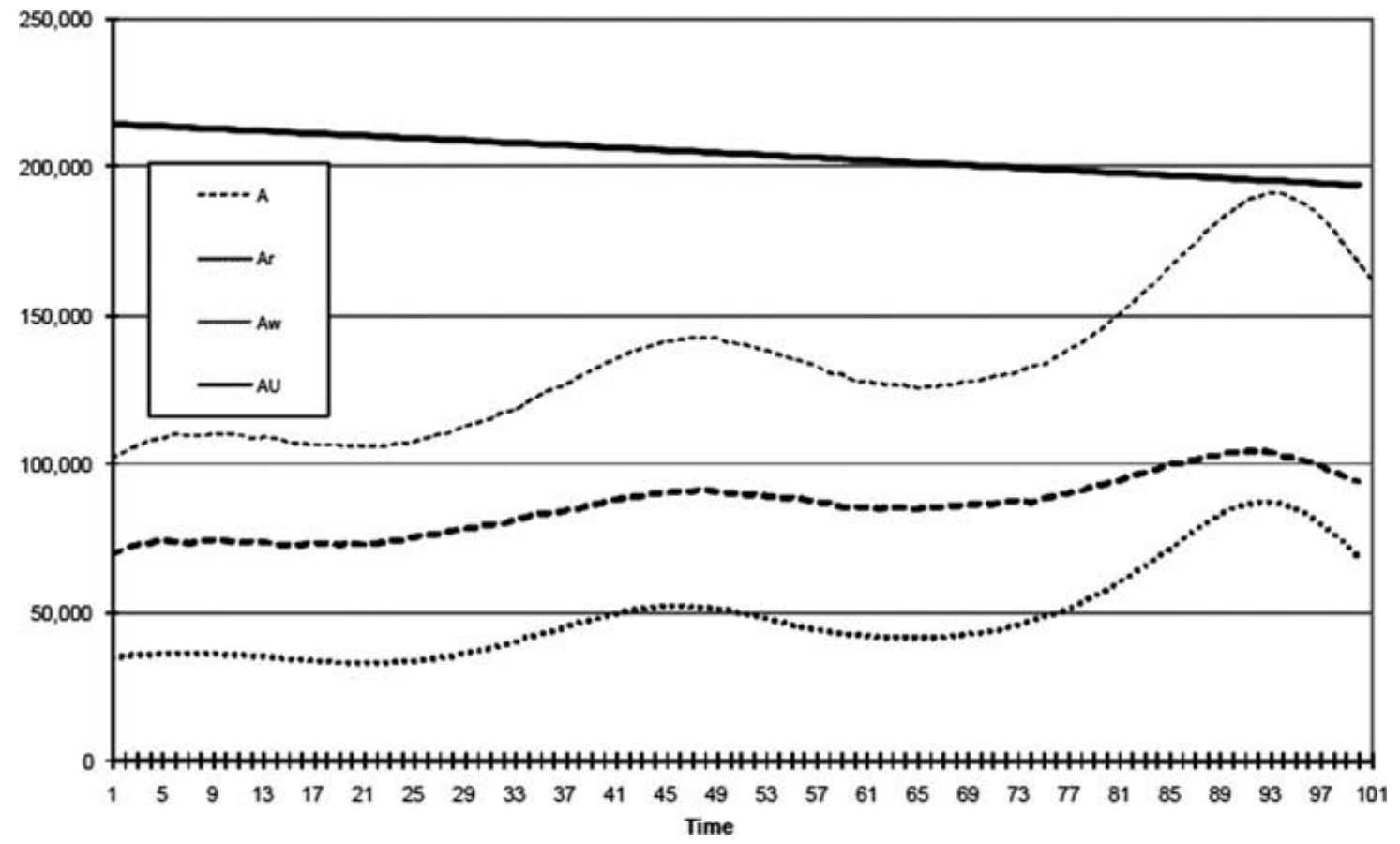

Economic systems modeling for sustainable ecosystems Richardson et al.

The dark dashed curve displays how many hectares were planted to irrigated rice and the dark dotted curve indicates the same for rainfed wheat. Notice that both register initial upswings in these crops' business cycles, which, when added together, produce the light dashed curve of total area under crops. Even toward the end of the century, the final boom conditions are not sufficiently prosperous for the available land constraint (dark solid line) to bind. However, this land constraint (together with the rainfall constraint) was forced down until it did bind, for purposes of the simulation exercise policy implications reported below.

There are already at least two policy implications thatmay be drawnfromtheresultsof exercisingeven this simple dynamic, nonequilibrium, nonoptimizing (in short, nonneoclassical), and profitability-driven simulation model of a generic regulated river basin's ecology and economy. First, experimental simulation runs, in which the land and rainfall constraints are forced to bind, indicate that rainfed crops benefit from increased resource scarcity
Figure 2. Land endowment and area planted (hectares). A is the total area under crops, Ar is the area of irrigated rice, Aw is the area of rainfed wheat, and $\mathrm{AU}$ is the total amount of land available for cropping.

thepolicydilemma of whether to retire the massive past investments in public and private irrigation infrastructure in Australia, plus the protection and subsidies provided to irrigated crops like pasture, rice, and cotton. A case in point concerns the world's largest cotton plantation on one of the biggest ever private irrigation projects. Cubbie Station is located in the north of the MDB on a Queensland river that feeds into the Darling and, ultimately, the Murray. Past irrigation infrastructure investments (plus dependent business enterprises and regional communities that have sprung up) create dilemmas about using the station's water entitlements for reviving the fortunes of long-established smaller irrigation

'If the full economic value of water had to be paid by irrigators, it would be obvious to all that the MDB possesses no natural competitive strength in producing irrigated pasture, cotton and rice for export, unlike countries such as China, India, Pakistan, and Turkey (cotton), and Thailand, Myanmar, Cambodia, and 
farmers downstream of Cubbie, or instead reviving the MDB's threatened ecosystem. Irrigation farmers below Cubbie (in New South Wales, Victoria, and South Australia) are being denied benefit of the water in the current situation, but if the government buys the Cubbie entitlements and retires them for the benefit of the ecosystem, then the below-Cubbie farmers will still be no better off.

Second, other experimental simulation runs indicate that whenever the RBC raises their water price "taxation rates" in response to droughts, this helps ameliorate business cycle volatility over the long term. Suchreductionsin the volatility of investment, realized profitability (hence lower risk premia) and output may actually benefit irrigation farmers, provided their average financial return on capital remains above their new, lower, average opportunity cost of capital. Here is an example of tax-funded water sustainability measures being consistent with the continuing sustainable profitability of irrigated agriculture. This important issue is reflected in simulation experiments by less severe troughs in recessions for the irrigated crop. The implications from this provide support for policy intervention due to systemic failure in the economic system as a result of ecological pressures.

\section{Conclusions and future work program}

We have reviewed the main features of a fresh policy-oriented economic modeling approach and suggest a new synthesis of ecology and economics in a generic RBM that is suitable for addressing some of the most pressing challenges we will face in the next 40 years. Any synthesis modeling approach must represent the economy as a "far from equilibrium," nonlinear CAS whose emergent properties stem from the interactions between a large number of distinct functional elements. This allows environmental systems to be fully incorporated in a

' Another more recent example of a policy dilemma in the MDB is the release by the Murray-Darling Basin Authority (MDBA) of its Guide to the proposed basin plan on October 11, 2010. In its effort to propose a return of significant environmental water flow back to the river basin, the authority has raised the ire of the irrigation farmers who need this very water for the economic and social survival of their rural communities. For details, see the MDBA Web site at http://www.mdba.gov.au.

self-consistent framework. Despite the shortfalls of neoclassical economic theory, there has been a recent convergence of approaches to the study of environmental and economic systems that provides opportunities for progress.

The basis of a synthetic modeling approach is illustrated with a simple RBM of a region resembling the MDB in southeastern Australia. Experimental runs of the model demonstrate the dynamical behavior of the system as well as the potential of the synthesis to provide support for policy. These policy implications should be regarded as tentative, given the exploratory nature of this "proof of concept" model. However, the RBM nonetheless captures some of the complex feedbacks and other interactions within and between the ecology and economy of a generic regulated river basin. This RBM model conforms to the nine features required, but rarely achieved, for an ecological-economic integrated dynamic model as specified by van den Bergh and Nijkamp.

Inevitably, there are shortfalls of the model as it is presented here, and these are opportunities for further progress. For example, the model includes only a narrow range of economic sectors (rainfed and irrigated crop production) and should be extended to include other sectors including the livestock, animal fodder, orchard, and forest industries. There also should be submodels for secondary and tertiary industries. We have used a consumption function for imports, but this should be replaced with a consumer demand equation for each domestic and imported commodity by farmers, other business owners, workers in different skill classes, and the unemployed. Furthermore, the lagged debt:equity ratio should affect farmers' investment in areas planted, plus land and irrigation infrastructure, but asyetitdoesnot.Farmareasshouldbechangedfrom theoretical "standard farms" of minimum economic size to an empirical range of farm sizes. Practical application to the MDB also requires that we integrate a reliable model for river flow and management. The resulting model will be sufficiently complex to require calibration against historical data to obtain the required parameterization using the PEST software (www.parameter-estimation.com).

The model as presented is generic and therefore transportable in principle to any 
ecological-economic regime. A particularly important aspect for future study is how the behavior of the model changes as greater complexity and spatial scales are introduced. Ecological models that attempt to approach global scales look very different from those applied at local and regional scales. ${ }^{29}$ It is likely that this will also be true for fully coupled economic models too. By studying the behavior of models like the one presented here as complexity grows, we can test the sensitivity to the details of the relevant interactions captured in the model. As in the study of interaction networks in other disciplines it may be that as complexity increases the sensitivity to micro-scale detail declines. In such a case, there is a logical conclusion to the level of additional data and knowledge that is required and this will provide exciting new insights into the level of granularity that is required in large-scale (more complex) models compared with smaller-scale (less complex) models. This in turn will provide insight into how small-scale models may be embedded in a description of the macro-scale economics for the purpose of local and regional scale decision making and forecasting. 
We believe that the shortfalls listed can be overcome and that this approach offers the potential to develop further into an operational model that can aid in an instrumental analysis of policy development as described in this paper. Given the impending pressures on environmental resources, it will be important to progress this as soon as possible.

\section{Appendix A: the river basin economy}

Some key relationships in the computer model of the river basin economy are set out below. Note that "pa" refers throughout to "per annum." All rice and wheat produced is exported, with virtually all inputs to production and commodities consumed being imported. The structural form of the model is a system of 158 equations and identities, comprising 47 for the rice submodel, 45 for the wheat submodel, and 66 for the macroeconomic section.

With the help of just 20 Greek letter parameters, these relationships mutually determine all quantities, prices, and values together with the realized rates of profit on capital ( $r r t \%$ pafor riceand $r w_{t} \%$ pa for wheat).

Farmers have static expectations, that is, they expect to realize $\mathrm{rrt}-1 \%$ pa on capital devoted to rice and rwt $-1 \%$ pa on capital devoted to wheat. One or both sets of farmers may not realize their expectations at harvest/sale time in any given year, of course; this is primarily what drives the economy's dynamics.

The river basin's “endowment" of arable land, suitable for raising either crop, is fixed at $A E_{t}$ hectares. Potential irrigation water $(H i p t$ gigaliters pa for rice) and normal rainfall water (Hrnt gigaliters pa for wheat) are also fixed in quantity.

Investment in area planted (hectares pa)

$$
A r_{t}=A t-1\left(1+<\left[r r_{t-1}-n r_{t}\right]\right) \text { for rice. }
$$

$$
A \mathrm{~W}_{t}=A \mathrm{~W}_{t-1}\left(1+<\left[r \mathrm{~W}_{t-1}-n \mathrm{~W}_{t}\right]\right) \text { for wheat. }
$$

If $A r_{t}+A w_{t}>A E_{t}$ the crop with the bigger expectation of profitability $\left(r_{t}-1 \% \mathrm{pa}\right)$ gets all the area it wants and the balance goes to the other crop. The two $n_{t} \%$ pa normal profit rates comprise the common interest rate plus a square brackets is the "profitability gap" between expected return on capital and opportunity cost of capital. As this gap widens and narrows, so the relevant area cultivated expands and contracts.

Investment in land and water (dollars pa)

$$
I r_{t}=I_{t-1}\left(1+<\left[r r_{t-1}-n r_{t}\right]\right) \text { for rice. }
$$

\section{Investment in land (dollars pa)}

$$
I \mathrm{~W}_{t}=I \mathrm{~W}_{t-1}\left(1+<\left[r \mathrm{~W} t-1^{-} n \mathrm{~W} t\right]\right) \text { for wheat. }
$$

\section{Wage rate (dollars/worker pa)}

$\mathrm{W}_{t}=\mathrm{W}_{t-1}\left(1+\varepsilon\left[e_{t}-1\right]+\mathrm{p} g p_{t-1} y g q_{t}\right)$ and $\mathrm{W}_{t} \geq$ Wt-1 with $e_{t}=L_{t} / N_{t}$ being the labor utilization ratio, $g p_{t-1}$ last year's domestic inflation rate, and $g q t$ the growth rate of labor productivity. The inequality ensures that, unlike real wage rates, average money wage rates never fall (as in real-world advanced economies).

\section{Crop produced (tonnes pa)}

$Q_{t}=A_{t-1} b_{t}$ for both crops, where crop yield (tonnes/hectare) is $b_{t}=b_{t-1}\left(1+g b_{t-1}\right)$ without water constraints, but otherwise is reduced by the fractions Hirt/Hipt for rice and Hrat $/ H r n_{t}$ for wheat, where the numerators are irrigation water released and actual rainfall water, respectively. The variable $g b_{t-1}$ is last year's growth rate of crop yield, which rises at the same rate as real crop yield investments (in constant dollars pa). These yield-raising investments comprise land improvements by the farmers themselves, plus government expenditures on research and agricultural extension by the RBC. 


\section{Realized profit (dollars pa)}

Oneach crop,thisisSalesRevenue $\left(Q_{t}\right.$ times the export price) minus the variable cost of wages, seed, fertilizer, fixed asset rentals, and RBC water and carbon charges.

\section{Employment (workers pa)}

$L_{t}=Q_{t} / q_{t}$ for both crops, where labor productivity ( $q t$ tonnes/worker) grows at the fixed rate $(g q t$ \%pa). The economy's workforce ( $N t$ workers pa) also grows at a fixed rate ( $\left.g N_{t} \% \mathrm{pa}\right)$.

\section{Conflicts of interest}

The authors declare no conflicts of interest.

\section{References}

1. Moriarty, P. \& D. Honnery. 2009. What energy levels can the Earth sustain? Energy Policy 37: 2469-2474.

2. Anon. 2004. Soil and trouble. Science 304: 1614-1615.

3. Connor, L., S. Freeman \& N. Higginbotham. 2009. Not just a coalmine: shifting grounds of community opposition to coal mining in south eastern Australia. Ethnos 74: 490-513.

4. Crane, P. \& A. Kinzig. 2005. Nature in the metropolis. Science

308: 1225.

5. Bettencourt, L.M.A. et al. 2007. Growth, innovation, scaling, and the pace of life in cities. Proc. Natl. Acad. Sci. USA 104: 7301-7306.

6. Moriarty, P. 2002. Environmental sustainability of large Australian cities. Urban Pol. Res. 20: 233-244.

7. Smith, G.J. \& J. Scott. 2006. Living Cities: An Urban Myth? Government and Sustainability in Australia.

Rosenberg. Dural.

8. Jain, A. \& J. Courvisanos. 2009. Urban growth centres on the periphery: Ad hoc policy vision and research neglect.

Australasian J. Region. Stud. 15: 3-26.

9. Angel, S., S.C. Sheppard \& D.L. Civo. 2005. The

Dynamics of Global Urban Expansion Washington, DC.

10. Waring, T.M. 2010. New evolutionary foundations: theoretical requirements for a science of sustainability. Ecol.

Econ.

69: 718-730.

11. Tschirhart, J. 2009. Integrated ecological-economic models. Annu. Rev. Res. Econ. 1: 381-407.

12. Ayres, R.U. 2008. Sustainability economics: where do we stand? Ecol. Econ. 67: 281-310.

13. Baumgartner, S. \& M. Quaas. 2010. What is sustainability economics? Ecol. Econ. 69: 445-450.

14. May, R.M. \& A. MacLean, Eds. 2007. Theoretical Ecology: Principles and Applications. Oxford University Press. Oxford. pp. 272.

15. Bousquet, F. \& C. Le Page. 2004. Multi-agent simulations and ecosystem management: a review. Ecol. Model. 176: 313-332.

16. Green, D.G. \& S. Sadedin. 2005. Interactions matter- complexity in landscapes and ecosystems. Ecol. Complex. 2: $117-$

130.

17. Driscoll, D.A. 2007. How to find a metapopulation. Can. J. Zool.-Rev. Can. Zool. 85: 1031-1048.

18. Caron-Lormier, G. et al. 2009. How might we model an ecosystem? Ecol. Model. 220: 1935-1949.

19. Sole, R.V. et al. 1999. Criticality and scaling in evolutionary ecology. Trends. Ecol. Evol. 14: 156-160.

20. Levin, S.A. 2005. Self-organization and the emergence of complexity in ecological systems. Bioscience 55: 1075-1079.

21. Marquet, P.A. et al. 2005. Scaling and power-laws in ecological systems. J. Exp. Biol. 208: 1749-1769.

22. Cianciaruso, M.V. et al. 2009. Including intraspecific variability in functional diversity. Ecology 90: 81-89.

23. Drossel, B. 2001. Biological evolution and statistical physics. Adv. Phys. 50: 209-295.

24. Levin, S.A. 1998. Ecosystems and the biosphere as complex adaptive systems. Ecosystems 1: 431-436. 25. Hooper, D.U. et al. 2005. Effects of biodiversity on ecosystem functioning: a consensus of current knowledge. Ecol. Monogr. 75: 3-35.

26. Caliman, A. et al. 2010. The prominence of and biases in biodiversity and ecosystem functioning research. Biodivers.

Conserv. 19: 651-664.

27. Meysman, F.J.R. \& S. Bruers. 2010. Ecosystem functioning and maximum entropy production: a quantitative test of hypotheses. Philos. Trans. R. Soc. B-Biol. Sci. 365: 1405- 1416.

28. Kleidon, A. 2010. A basic introduction to the thermodynamics of the Earth system far from equilibrium and maximum entropy production. Philos. Trans. R. Soc. B-Biol. Sci. 365: 1303-1315.

29. Kleidon, A., Y. Malhi \& P.M. Cox. 2010. Maximum entropy production in environmental and ecological systems introduction. Philos. Trans. R. Soc. B-Biol. Sci. 365: 1297-1302.

30. Polasky, S. \& K. Segerson. 2009. Integrating ecology and economics in the study of ecosystem services: some lessons learned. Annu. Rev. Resour. Econ. 1: 409-434.

31. Farmer, J.D. \& D. Foley. 2009. The economy needs agent-based modelling. Nature 460: 685-686.

32. May, R.M., S.A. Levin \& G. Sugihara. 2008. Complex systems - ecology for bankers. Nature 451: 893-895. 33. Dasgupta,P.\&K.-G.Maler,Eds.2004. The Economics of Non-Convex Ecosystems. Kluwer Academic Publishers. Dordrecht.

34. Dasgupta, P. \& G. Heal. 1974. The optimal depletion of exhaustible resources. Rev. Econ. Stud. 41: 3-28.

35. Hotelling, H. 1931. The economics of exhaustible resources.

J. Political Econ. 39: 137-175.

36. Colander, D., Ed. 1996. Beyond Microfoundations: Post Walrasian Macroeconomics. Cambridge University Press. Cambridge.

37. Blume, L.E. \& S.N. Durlauf, Eds. 2006. The Economy as an Evolving Complex System III: Current Perspectives and Future Directions. (Santa Fe Institute Studies on the Sciences of Complexity). Oxford University Press. Oxford. 38. Davies, D. 2004. Economia. ABC Books. Sydney. 
39. Rosser, J.B. 1999. On the complexities of complex economic dynamics. J. Econ. Perspect. 13: 169-192.

40. Courvisanos, J. \& C. Richardson. 2006. Corridor of viability: complexity analysis for enterprise and investment. In Complexity, Endogenous Money and Macroeconomic Theory: Essays in Honour of Basil J Moore. M. Setterfield, Ed.: 99-118. Edward Elgar. Cheltenham.

41. WCED. 1987. Our Common Future.Oxford. Oxford.

42. Vercelli, A. 1998. Sustainable development, rationality and time. In Sustainable Development: Concepts,

Rationalities and Strategies. S. Faucheux, M. O’Connor \& J. van der Straaten, Eds.: 259-276. Kluwer Academic Publishers. Dordrecht.

43. Costanza, R. \& H. Daly. 1992. Natural capital and sustainable development. Conserv. Biol. 6: 37-46.

44. Courvisanos, J. 2005. A post-Keynesian innovation policy for sustainable development. Int. J. Environ., Workplace

Employment 1: 187-202.

45. Lowe, A. 1976. The Path of Economic Growth.

Cambridge University Press. Cambridge.

46. Oakley, A. 1987. Introduction: Adolph Lowe's

contribution to the development of a political economics. In

Essays in Political Economics: Public Control in a Democratic Society.

A. Lowe, Ed.: 1-24. New York University Press. New York. 47. Forstater, M. 1999. Working backwards: instrumental analysis as a policy discovery procedure. Rev. Political Econ. 11: $5-18$.

48. Freeman, C. \& C. Perez. 1988. Structural crises of adjustment, business cycles and investment behaviour. In Technical Change and Economic Theory.G.Dosi, et al., Eds.: 38-66. Pinter. London.

49. Courvisanos, J. 1996. Investment Cycles in Capitalist Economies: A Kaleckian Behavioural Contribution.Cheltenham. Edward Elgar.

50. Richardson, G. 1960. Information and Investment: A

Study in the Working of the Competitive Economy.

Oxford University Press. Oxford.

51. Helm, D. \& D. Pearce. 1991. Economic policy towards the environment: an overview. In Economic Policy Towards the Environment. D. Helm, Ed.: 1-24. Blackwell. Oxford. 52. Kalecki, M. 1986. Selected Essays on Economic Planning. Cambridge University Press. Cambridge.

53. Rockstrom, J. et al. 2009. A safe operating space for humanity. Nature 461: 472-475.

54. DSE. 2009. Achieving Target 155. Victorian

Government. Melbourne.

55. Richardson, C. \& P. Romilly. 2008. Investment functions and the profitability gap. J. Post Keynesian Econ. 31: 3556.

56. Courvisanos, J. 2009. Optimise versus satisfice: two approaches to an investment policy for sustainable development. In Post Keynesian and Ecological Economics: Confronting Environmental Issues. R. Holt, S. Pressman \& C.L. Spash, Eds.: 279-300. Edward Elgar. Cheltenham, UK and Northampton, MA.

57. van den Bergh, J. \& P. Nijkamp. 1991. Operationalizing sustainable development: dynamic ecological economic models. Ecol. Econ. 4: 11-23. 